\title{
Government Capacity, Societal Trust or Party Preferences? What Accounts for the Variety of National Policy Responses to the COVID-19 Pandemic in Europe?
}

\author{
Dimiter Toshkov ${ }^{1}$, Kutsal Yesilkagit and Brendan Carroll \\ (Institute of Public Administration, Faculty of Governance and Global Affairs, Leiden University, The Netherlands)
}

This version: 29 April 2020.

An updated and revised version was published by the Journal of European Public Policy on 17 May 2021 and is available (open access) at: https://doi.org/10.1080/13501763.2021.1928270

\begin{abstract}
European states responded to the rapid spread of the COVID-19 pandemic in 2020 with a variety of public policy measures. Governments across the continent acted more or less swiftly to close down schools, restrict arrival into their countries and travel within their territories, ban public meetings, impose local and national lockdowns, declare states of emergency and pass other emergency measures. Importantly, both the mix of policy tools as well as the speed with which they were enacted differed significantly even within the member states of the European Union. In this article we ask what can account for this variation in policy responses, and we identify a number of factors related to institutions, general governance and specific health-sector related capacities, societal trust, government type, and party preferences as possible determinants. Using multivariate regression and survival analysis, we model the speed with which school closures, national lockdowns and states of emergency were announced. The models suggest a number of significant and often counterintuitive relationships: we find that more centralized countries with lower government effectiveness, freedom and societal trust, but with separate ministries of health and health ministers with medical background acted faster and more decisively. These results are important in light of the large positive effects early policy responses likely had on managing the impact of the pandemic.
\end{abstract}

${ }^{1}$ Corresponding author: email: d.d.toshkov@,fgga.leidenuniv.nl 


\section{INTRODUCTION}

The first three cases of coronavirus disease 2019 (COVID-19) in Europe were reported on 24 January 2020 in France (Spiteri et al. 2020). Within a matter of weeks, the virus had spread across the continent, with cases also confirmed in Germany, Finland, Belgium, Italy, Spain, Sweden and the United Kingdom (UK). France reported the first death from COVID-19 on 15 February 2020, but it was Italy that emerged as the center of the pandemic in Europe, with cases quickly jumping to 1,700 by the end of February and deaths starting to climb up relentlessly from the beginning of March.

As the grave dangers and unprecedented scale of the pandemic gradually became clear to politicians and policy makers, on 4 March 2020 Italy became the first European country to announce the closure of all its schools in an effort to contain the spread of the virus. As cases and deaths continued to increase exponentially, Italy initially imposed local quarantines and then extended the measures to the national level, ultimately imposing a strict national lockdown, announced on 11 March 2020. Other European countries quickly followed suit, as they watched their own number of COVID19 cases increase and deaths in Italy rise to more than a hundred every day. By 17 March, almost all European countries had closed down their schools, with the notable exceptions of the UK, which followed suit later a week later, and Sweden, which remained the only EU member state not to impose this measure nationally. Regional and national lockdowns with a varying degree of strictness followed - most EU countries had one in place by the end of March, complemented with other policy measures, such as restrictions on arrival within the country and on free movement within its territory, backed in many cases by the adoption of emergency laws and declarations of states of emergency.

Despite the fact that all European countries announced some restrictive policy measures during these few faithful weeks in March 2020, both the policy mix and the timing of adopting the policies differed even within the relatively similar set of EU member states (plus the UK, Switzerland, Norway and Iceland). As it turned out later, even a difference of a couple of days in limiting social contacts could have important impact on the speed with which the coronavirus spread and the death toll it led to. In absence of an effective vaccine and with many countries having very limited health care capacities, the pandemic provoked a variety of policy responses by national governments

worldwide directed towards social distancing. In this article, we ask the research question: What factors can account for the variety of policy responses and their timing to the COVID-19 pandemic in Europe in the early stages of the pandemic before April 2020?

To answer this question, we build on existing theories of the public policy process, regulation, and decision making in order to identify a number of factors that could have influenced how 
governments have approached the management of the coronavirus pandemic. The set of potentially important factors we study is large and covers variables related to political institutions, general governance capacity, specific health care sector capacities and organizational arrangements, political party ideologies and preferences, and societal factors, such as interpersonal trust, trust in government, and the overall freedom in a country.

We analyze the possible associations of these factors with three aspects of the national policy responses: the closing of schools, the imposition of national lockdown, and the declaration of state of emergency. We use linear regression and event history (survival) statistical methods to model the number of cases a country had before adopting any of these three policy measures and the number of days between the first registered case and the policy decision.

The models suggest a number of significant and often counterintuitive relationships: we find that more centralized countries with lower government effectiveness, freedom and societal trust, but with separate ministries of health and health ministers with medical background acted faster and more decisively. These results are best regarded as associational rather than causal. But for some variables government effectiveness, in particular - we build more complex multivariate models that try to isolate the causal effect of the variable from other possibly confounding influences, and we find that the relationship is robust to including GDP per capita and indicators of the health care capacities in the models. Still, given the exploratory nature of the study, our results are best conceived as identifying promising bypotheses about the determinants of the national policy responses to the COVID-19 pandemic in Europe rather than estimating causal effects or testing theories about the policy process.

The influence of governmental decision making during the coronavirus crisis on the course and consequences of the pandemic is substantial. We focus on the speed and types of policies adopted, which cannot be equated with the quality of the policy response as such. While the policy responses should be timely and appropriate, there are other considerations that come into play when assessing their quality, and speed might not be the most important. When it comes to managing the early stages of the pandemic, however, it appears that the earlier countries acted and the more comprehensive the restrictions they adopted, the more effective they were in slowing down and containing the spread of the virus (for evidence from a U.S. state, see Friedson et al. 2020). Therefore, understanding the factors that enhanced or impeded the speed of policy making in response to the coronavirus is an important element in preparing more effective and efficient governance structures for dealing with pandemics and other crises. 


\section{POLICY RESPONSES TO THE COVID-19 PANDEMIC: TOOLS AND TIMING}

Following the first reports of confirmed cases in their countries or regions, governments across Europe and the world adopted a series of policy measures to mitigate the coronavirus outbreak ${ }^{2}$. Policy responses have included, among others, the mandatory closure of schools, requirements for telecommuting when possible, the closure of borders, suspension of flights, prohibitions on public events of certain size, and restrictions on the freedom of movement of private citizens. Often several measures have been introduced simultaneously and have been accompanied by a formal declaration of a state of emergency or the passing of emergency legislation, either of which may grant the government extraordinary decision-making authority.

In this study, we limit our attention to three of the most common types of measures governments have taken to slow the spread of the pandemic and to ensure their own responsive and effective action. These are 1) school closures, 2) national lockdowns, and 3) the declaration of a state of emergency or the passing of equivalent legislation. European governments have rarely applied these measures in peacetime, contributing to their interest from a social scientific perspective. School closures are defined as mandatory closure of most primary and secondary schools nationally, even if some categories of establishments (e.g. kindergartens) are excluded and if the schools remain open for a small section of society (e.g. children of workers in critical sectors, such as healthcare). National lockdowns are defined as comprehensive restrictions on the movement of citizens with stay-at-home orders, closing down of shops, businesses and in some cases public spaces, applied to the territory of the country as a whole (rather than only to particular regions). Emergency measures include the declaration of a formal state of emergency, but also other measures with similar effects, such as emergency laws that give temporary powers to the executive or particular organizations and committees.

For each country and each policy, we record the date when each kind of measure was announced. Table A1 in the Supplementary Material gives a descriptive overview of the dates on which these three measures were adopted by the governments. We obtain the timing of schools closures and national lockdowns from a variety of sources, starting with the Oxford COVID-19 Government Response Tracker $^{3}$, which collects information about several measures that national governments

\footnotetext{
2 See for an overview of policy responses across various countries: 'Country Responses to the Covid10 Pandemic', Cambridge Core Blog (https://www.cambridge.org/core/blog/tag/country-responses-to-the-covid19-pandemic/), consulted on 27 April 2020 and previous days.

3 https://www.bsg.ox.ac.uk/research/research-projects/coronavirus-government-response-tracker
} 
throughout the world have applied in response to the virus (Hale et al. 2020). When the Tracker records a missing value for one of the countries in our sample, we have searched government websites and media accounts for other evidence of the introduction of measures, mirroring the approach used to collect the Tracker data ${ }^{4}$. For states of emergency and equivalent legislation, we have relied on reports from Cambridge Core Blog on countries' responses (Oliver 2020) to the pandemic, supplemented with additional governmental and press-related sources when reports are not available for a particular country. Combining these sources, we have identified measures for each country in our sample or indicate that no measures of a particular type have been applied as of the time of writing.

Figure 1 below shows the timing of the three types of policy measures for the set of EU+ countries (the EU member states, plus the UK, Switzerland, Iceland and Norway), which are the focus of our analyses. The horizontal axis tracks time in days between 1 March and 1 April 2020, and the vertical axis indicates the cumulative number of confirmed COVID-19 cases countries had (on a log scale) ${ }^{5}$. Each country code shows when (in terms of date) and at what stage in the pandemic (in terms of confirmed cases) the country was when it adopted the policy measure. Countries that did not adopt the measure are shown with their number of cases as of 1 April 2020.

The figure offers several observations. First, we see that many countries announced school closures while their levels of confirmed cases were relatively low. From the early adopters, Italy is an exception. Whereas the governments of Lithuania, Cyprus, Malta, Slovakia, and Latvia closed their schools when they only had just 10 or fewer confirmed cases of COVID-19 infections in their countries $^{6}$, it took 3500 or more confirmed cases for the French (3661), Spanish (4231), German (4838), and British (5683) governments to close down schools. Countries like Greece (90), Denmark (264), Belgium (314), and Norway (489) can equally well be considered as relatively early responders to the spread of the virus. The Swedish government is the sole exception as it refrained from imposing this measure with almost 8500 cases on 1April. The United Kingdom has been a relative late adopter as well. Initially the government gave the message that the country would strive for mitigation and delaying the spread of the virus. The UK government's approach to the pandemic ought to be

\footnotetext{
4 A comprehensive overview of Coronavirus policy response trackers is available at https://lukaslehner.github.io/covid19policytrackers/.

${ }^{5}$ For all analyses reported in this article we obtain the daily number of confirmed COVID-19 related cases and deaths per country from the European Centre for Disease Prevention and Control (ECDC). More information on the methodology is available at https://www.ecdc.europa.eu/en/covid-19-pandemic, We conduct the analyses with the version of the data as of 26 April 2020.

${ }^{6}$ Bulgaria is another country that acted early to close down schools, and it is interesting to note that schools were already closed previously in the year in response to a flu outbreak.
} 
'evidence-based'. The government turned to a substantially more stringent approach following public disapproval for its approach and insights from studies on the Chinese case. ${ }^{7}$
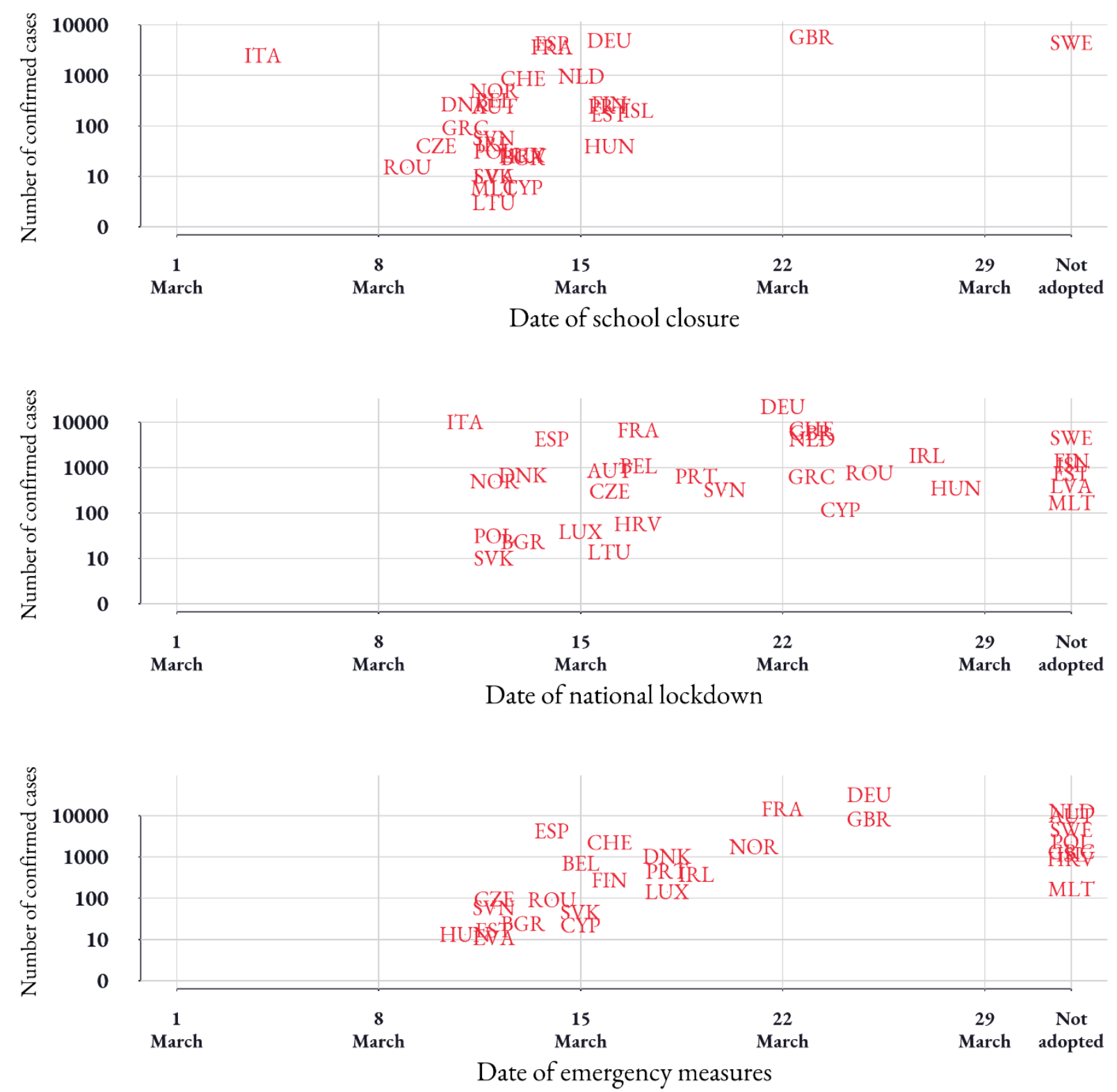

Figure 1. Cumulative number of COVID-19 cases and timing of policy restrictions in Europe

7 Michal Cainan, "England's Response to the Coronavirus Pandemic", Cambridge Core Blog, update of 6 April 2020, https://www.cambridge.org/core/blog/2020/04/06/englands-response-to-the-coronavirus-pandemic/, consulted on 27 April 2020. 
As for lockdown measures, we find that the variation between countries is larger. Whereas in the case of school closures the majority of closing decision fell within a time of a single week, the lockdown decisions are spread over a period of two weeks. But overall, except in the cases of Italy and Spain, we find countries with relatively lower confirmed cases on the forefront of imposing restrictive lockdowns. So, in Slovakia, Poland, and Bulgaria, central governments imposed a lockdown with reported cases between only 10 to 30 cases. It is important to note that in most countries lockdown measures were implemented in a stepwise manner, starting initially with a partial lockdown and then moving up to a full lockdown. The Swiss case is an illustration of this. The Swiss Federal Council first prohibited gatherings of 1000 persons on 28 February, extended it to over 100 persons on 14 March, and then, two days later, it invoked the Federal Epidemics Act to declare an "extraordinary situation". Under these powers, the Federal Council put a ban on migration, closed down schools and universities, mobilized the armed forces, and restricted gatherings up unto five persons ${ }^{8}$.

Another observation is that six countries (Finland, Malta, Latvia, Estonia, Sweden and Iceland) had not imposed a national lockdown by the 1 st of April. While not going as far as to impose a lockdown, these countries did, however, apply certain stringent measures to curb the free movement of persons within the country. Finland, for example, restricted travel to and from its capital region. The Swedish government's stance towards the pandemic stands out for its reliance on measures of a more voluntary nature. The government there has refrained from taking any restrictive measures so far and works through issuing recommendations rather than orders or decrees. Malta, finally, has reportedly been able to contain the spread of the virus by lack of direct connections to China and the imposition of strict travel controls, initially, for persons from Italy and later to other European countries. The Maltese government has not issued a full national lockdown order by 1 April, but it did close schools and day centers for the elderly, and religious activities.

The last panel of Figure 1 shows the distribution of the adoption of emergency measures (a broader category than declaring a state of emergency). There is considerable variation when it comes to the timing of this measure as well, with some cases having more than 1000 case before resorting to emergency powers, other having a much lower number, and some did not announce such measures.

\footnotetext{
8 Philipp Trein and Victor G. Rodwin Wagner, "Switzerland's Response to the Coronavirus Pandemic", Cambridge Core Blog, update of 8 April 2020, https://www.cambridge.org/core/blog/2020/04/08/switzerlands-response-to-thecoronavirus-pandemic/, consulted on 27 April 2020.
} 


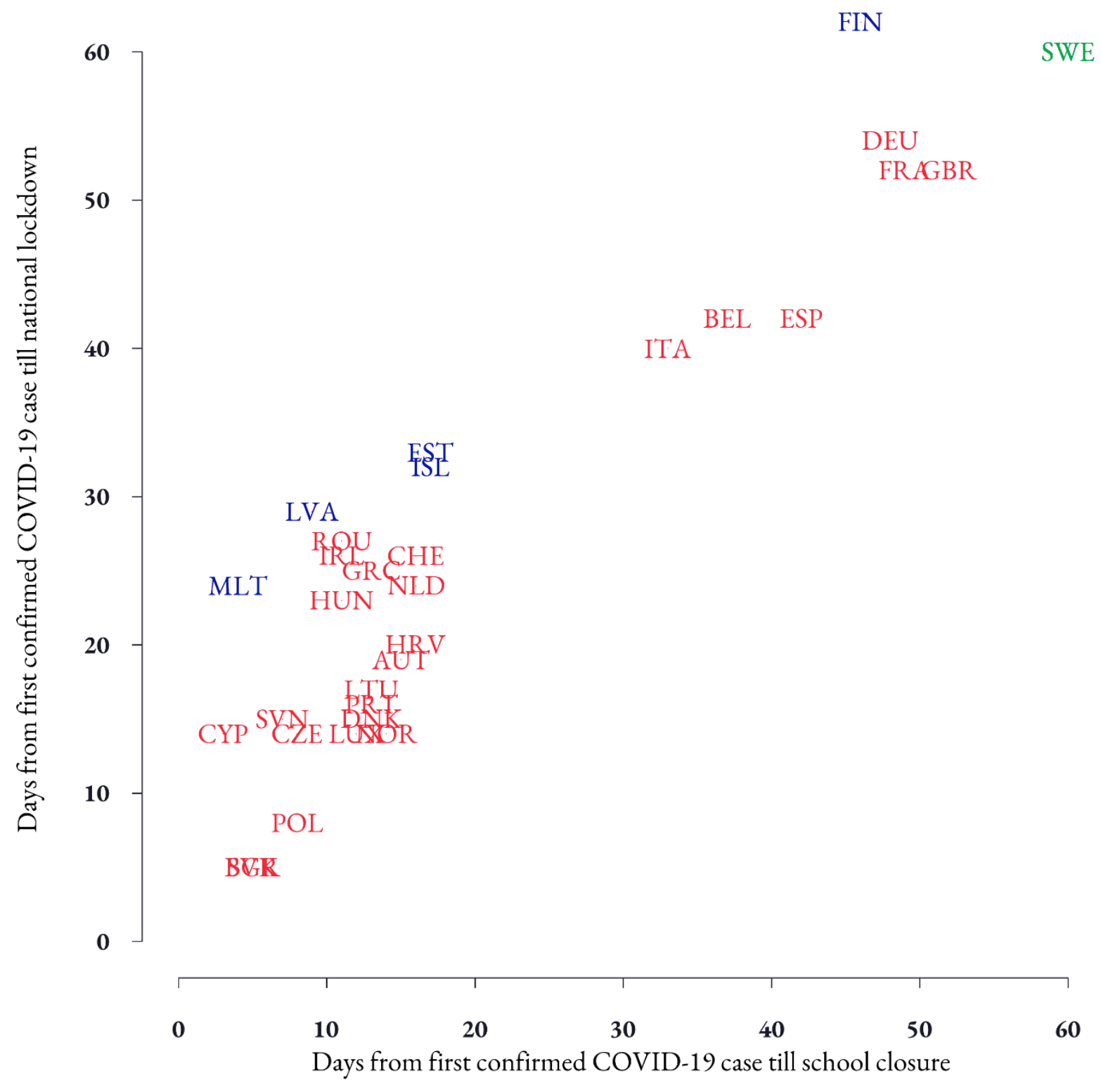

Figure 2. Time until policy restrictions since first confirmed COVID-19 cases (blue/green labels: cases censored as of 1 April 2020)

Figure 2 presents data on the timing of closing schools and national lockdowns in a different way to show the correlation between the two. Both axes of the figure track the number of days between the first confirmed COVID-19 case in the country and the announcement of the policy measures (if at all, see also Table A1 in the Supplementary Material). The figure also makes it clear that bigger countries took more time to adopt such measures. In view of this, we include population 
as a control variable in all models we report in this article. But this observation carries substantive importance as well: while it is to some extent expected that more populous countries should enact drastic restrictions on the freedoms of their citizens when a higher absolute number of people are infected from the virus than less populous countries, now that we know that the registered and confirmed number of COVID-19 cases was much lower than the real one and that a large share of the infected were asymptomatic, it seems that bigger countries have made bigger mistakes by waiting for their official number of cases to accumulate.

\section{WHAT ACCOUNTS FOR THE DIVERSITY OF POLICY RESPONSES? THEORETICAL CONSIDERATIONS}

We build on theories of the public policy process (e.g. Howlett, Perl, and Ramesh 2009), regulation (e.g. Baldwin, Cave, and Lodge 2011) and legislative decision making (e.g. Tsebelis 2011) to identify mechanisms and factors that can account for the timing and variety of policy responses adopted by the European governments in response to the coronavirus crisis. We choose to focus on factors that, in addition to theoretical relevance, have practical significance as well and/or have been discussed as possible determinants of the policy responses in the media and the broader public sphere.

We start from an actor-centered understanding of the policy-making process, and we focus on the role of the central government, and the executive in particular. Taking cabinets as the central decision-making actors is congruent with the general view in comparative politics and government studies that the majority of European parliamentary systems are characterized as systems whereby the executive is dominant vis-a-vis the legislature (King 1976; Rasch and Tsebelis 2011). This is even more so in times of crises (Boin and 't Hart 2012), though structures for crisis coordination vary within Europe and by type of crisis (Boeke 2018; Boin and Bynander 2015; Jabko 2019). The national cabinets, ministers, ministries and government agencies have been at the center of formulating and enacting the policy responses to the pandemic, even if some of the measures have required the approval of the legislatures and local governments have played a significant role in the implementation of the measures. In Europe, the crisis has been managed from the center of the executive branch; accordingly, our search for the determinants of the policy responses needs to concentrate there.

\section{Policy learning and diffusion}

Before we present the theoretical considerations about the possible effects of individual variables, we need to discuss the joined-up nature of governance in the EU and the inter-dependence of the policy 
responses of the national governments (Schimmelfennig, Leuffen, and Rittberger 2015). With regard to supranational influence from the EU itself, there has been little that has steered or constrained the national government policies. While European agencies, such as ECDC, have been collecting and disseminating COVID-19 related data and have formulated guidance and advice, there have been no particular EU hard laws adopted that have demanded or forbid particular policy measures at the national level (even the sacrosanct freedom of movement between member states has been temporarily curtailed in some cases).

Voluntary policy learning and horizontal policy diffusion, however, definitely have been important. European governments closely observed how the crisis was unfolding in the countries hit first - especially Italy - and were learning both about the scale of the threat of the pandemic, as well as about the feasibility of different policy responses and their likely effectiveness. The countries that suffered first from the spread of the coronavirus had to figure out the proper policy measures to contain the pandemic as they already struggled to deal with its impact on hospitalizations and mortality, while the rest had a bit more time to watch and take lessons. But the speed with which the pandemic spread to almost all European states left very little time for contemplation and analysis. The significant residual variation in the type and timing of policy responses across Europe adopted after Italy first closed downs its schools suggests that policy learning has not trumped the idiosyncrasies of national policy making completely. Hence, while we acknowledge the interdependent nature of policy making in a multi-level governance system, such as the EU, we consider that individual member states have retained sufficient autonomy in designing the national policies to allow for a cross-country comparative analysis ${ }^{9}$.

Turning to the individual country-level factors that we study, we organize the discussion by grouping the variables in several clusters: (1) general governance capacity, (2) health care specific

\footnotetext{
${ }^{9}$ In the statistical models we estimate we can address the possibility of non-independent national policy responses indirectly by including the absolute date of policy adoption as a covariate (on the assumption that adoptions later in time become more likely as countries observed the actions of others) or including the number of countries that have already adopted the policy as a time-varying covariate in the event history analyses. Unfortunately, with the available number of observations and the high collinearity between (1) the daily cumulative number of confirmed COVID-19 cases that a particular country has, (2) the number of confirmed cases that neighbouring countries have, and (3) the number of restrictive policies adopted by neighbouring countries, the analyses are underpowered to distinguish which of these variables are relevant and which not. That being said, analysis of the baseline hazard rate of policy adoptions reveals that the hazard significantly increased after the first couple of adoptions (see the Supplementary Material). Whether this is due to countries reacting solely to the growing number of their own confirmed cases or to learning from the experiences and policies of their neighbors is for now impossible to say.
} 
capacity and organization, (3) political institutions, (4) government type, (5) party-political ideology, and (6) societal factors.

\section{General governance capacity}

The first cluster of variables we analyze is related to the idea that the quality and timeliness of the policy responses depends on the general governance capacity of the countries (for a discussion of governance capacity during crises, see Christensen, Lægreid, and Rykkja 2016). To adopt appropriate policy measures to tackle the crisis, government need to have the capacity to detect the impeding health care threat, to monitor the development of the epidemic, to collect enough information to build predictive models and assess the risks, costs and likely effects of different possible policy responses, to formulate fast the technical and legal details of concrete policy proposals, to steer the policy proposals through the decision-making bodies, to communicate the policy measures effectively to the public, and to organize for implementation and enforcement of the measures. In structural terms, high governance capacity requires that experts are incorporated at each stage of the policy process, from the detection of the problem to be put on the government agenda, to the formulation of policy alternatives, to decision making, policy implementation and evaluation and may include norms of evidence-based policymaking (Boswell 2018; Meckling and Nahm 2018). High governance capacity implies that governments have wider range of policy tools at their disposal and are able to deploy these tools more swiftly, also because of the higher legitimacy the policy actions of such governments have in the eyes of the public. High governance capacity is underpinned by established rules and procedures for crisis detection and response, including the setup of specialized committees, agencies and other advisory bodies.

We operationalize general governance capacity using the Worldwide Governance Indicators provided by the World Bank (the most recent year available is 2018) ${ }^{10}$. In principle, six different dimensions measuring governance are available, but in practice they are very highly correlated within the set of European countries. Although we present results for Government Effectiveness, Rules of Law, Regulatory Quality and Control of Corruption, these dimensions capture essentially the same axis of variation in governance quality across Europe. In addition to the World Governance Indicators, we include the more specific score related to the incorporation of experts in policy making from the

\footnotetext{
10 The indicators and methodology are available from: https://info.worldbank.org/governance/wgi// (last consulted 24 April 2020).
} 
Strategic Governance Indicators provided by the Bertelsmann Stiftung. This score indicates the degree to which the government regularly takes into account advice from non-governmental experts early in the decision-making process. ${ }^{11}$ Finally, we include Gross Domestic Product Per Capita (adjusted for purchasing power and expressed in constant international US dollars, as provided by the World Bank) as a measure of the relative wealth of countries, on the assumption that institutionalized capacity that can be quickly deployed requires a lot of financial and other resources, inter alia to maintain a well-trained and properly paid civil service.

\section{Health care capacity and organization}

Next to general governance capacity we consider capacities specific to the health care sector. In particular, we focus on how governance of the health sector is organized and represented in the government organizational structure, whether the sector is politically represented in the cabinet by a medical professional, and on the number of hospital beds and intensive care units in the country.

The first health care sector variable that we consider is the organization of the health care portfolio. Cabinets differ in the way they have allocated portfolios between different ministerial departments. Some cabinets have a ministry of health care that is entirely devoted to health care issues. In other cabinets one finds the health care portfolio being part of a ministry with multiple portfolios, such as social affairs, welfare or employment. One can also come across ministerial departments in which healthcare is subsumed under other issues. This is the case when health care is part of a general ministry of, for example, home affairs. Portfolio design affects the prioritization of health care issues within organizations as well as on the cabinet agenda (Hammond 1986; Mortensen and GreenPedersen 2015). In 'single-sector' health portfolios or ministries, health care values and interests do not need to 'compete' with other non-health care related issues. Accordingly, the weight of healthcare issues increases with the presence of a single-sector ministry as in those cases a single minister who is on an equal footing with other portfolio holders is representing health care values and interests. We expect that central governments with single-sector health portfolios will adopt policy responses earlier than central governments with either multi-portfolio departments in central governments or ones that do not have a specialized health ministry.

\footnotetext{
11 The scores and methodology are available from: https://www.sginetwork.org/2019/Governance/Executive Capacity/Strategic Capacity/Expert Advice (last consulted 24 April 2020).
} 
A second sector-level factor that is of importance is the professional background of the minister that holds the healthcare portfolio. We expect that a cabinet in which the minister of health care is a medical professional will adopt policy measures more swiftly than governments where the health minister has a non-medical background. A minister who has medical background is expected to understand better the health and epidemiological issues surrounding the epidemic, to be more receptive to the opinions of medical experts and doctors directly engaged in treating victims of the virus, and to have more accurate impressions about the situation on the group level in hospitals and other care medical care facilities ${ }^{12}$. Having a reserved seat at the cabinet, a health minister with medical background can channel the concerns and views of the profession directly into the highest decisionmaking forum.

A different set of indicators of health care capacity that we examine is the number of hospital beds and intensive care units (ICU) that countries have at their disposal ${ }^{13}$. As many accounts from different countries report, cabinets attach high importance to the existing capacities of hospital care, which cannot be upgraded quickly to match the demands created from an exponential increase in the number of victims of the corona virus. Lower numbers of hospital beds, and ICU in particular, might make countries more cautious and more likely to adopt faster heavier restrictions in response to the threat of the pandemic. Simply put, if the capacity of the health care sector to deal with the consequences of a rapidly spreading virus is known to be low, government will be less likely to take chances with partial or delayed lockdowns and other restrictions. Public justifications of the policies adopted in Ireland and Greece also support this line of reasoning. However, the empirical evaluation of this argument is complicated by the fact that richer countries and ones with higher general governance capacity tend to have more hospital beds and ICU units as well.

\section{Political institutions}

The next set of factors we consider relate to the political institutions of the state and, in particular, to the vertical distribution of power within the state and the type of legislature. With regard to the vertical distribution of power, we expect that federal and decentralized countries will be altogether slower in their responses to the coronavirus crisis. At the political level, federal countries might require political

\footnotetext{
${ }^{12}$ In Ireland, the prime minister Leo Varadkar himself is a medical doctor and even rejoined the medical register and offered to help with the help service during the crisis (see the BBC report from 5 April 2020 at https://www.bbc.com/news/world-europe-52177696, last consulted 24 April 2020).

${ }^{13} \mathrm{We}$ combine intensive care unit (ICU) and intermediate care unit (IMCU) beds per 100,000 inhabitants from Rhodes et al. and obtain the overall number of hospital beds (per 1,000 inhabitants) from Wikipedia and other sources.
} 
compromises between the federal and regional-level authorities. Competences over different aspects of handling the crisis (health care, education, police, etc.) can be shared or distributed along the levels of government in complex ways that can impede the speed of policy formulation and require longer decision-making procedures, with the scope for gridlock and delay if preferences across levels diverge. Even when the preferences at the different levels are aligned, more time for coordination is still needed. At a more technical level, federal and decentralized states might experience problems in collecting timely and comparable data related to hospitalizations, deaths, virus prevalence, hospital capacities, etc. from the different constituent units. And there might be greater variety and anticipated difficulties in uniform implementation of any common policies decided at the federal level, which will limit what policy options are feasible.

Because not all of these mechanisms are specific to federations as such - strongly decentralized (like Spain) or devolved states (like the UK) can be subject to very similar problems, we employ two variables to measure the vertical distribution of power in a state. Federalism is a dummy variable that distinguishes between (con)federal (Belgium, Austria, Germany and Switzerland) and unitary states. Regionalism is a more fine-grained indicator that measures the degree in which a political system has devolved a certain number and variety of authorities to regional administrative levels, such as districts, provinces or municipalities. Regionalism, as measured by the Regional Authority Index ${ }^{14}$, has a wider range of variation. It is a continuous variable that ranges from 0 (a country without regional authorities) to 37.4 (the country with the most numerous regional authorities with the greatest autonomy, Germany) (Hooghe et al. 2016).

The other factor related to political institutions that we include is the type of legislature. We expect higher transaction costs, and thus a less timely policy response, when the legislature has two chambers, because legislation needs to be approved by both chambers and a lengthy bargaining between the two chambers might be involved, especially when different political majorities control the two chambers. The measure we use is a dichotomous variable for bicameral legislatures.

\section{Government type}

The next set of factors we study relates to the type of government in terms of its status (minority or majority, caretaker or not) and number of parties in government (one for a single-party cabinet and more in a governing coalition). These variables are related to the transaction costs of negotiating and

14 https://www.arjanschakel.nl/index.php/regional-authority-index 
adopting laws and policies in cabinet decision making. With a higher number of coalition partners, reaching a compromise policy decision becomes more difficult, takes more bargaining rounds and can run into a stalemate (Toshkov, Mäder, and Rasmussen 2020). Moreover, even when a compromise is found, it is more likely to embody a piecemeal solution with more vague provision open to interpretation and the discretion of implementing agents. This is even more so when different parties control ministries with different missions and constituencies to protect, such as Health Care and Economic Affairs, for example, or Education and Finance.

Minority governments face even greater hurdles for rapid policy making, because they have to build support coalitions for any law they want to pass through the legislature. Multiparty minority coalitions combine the challenges of both coalition and minority governments. At the same time, it should be noted that countries where coalition and minority cabinets are often found have established institutionalized mechanisms to mitigate the negative effects on the effectiveness of the policy making process (Anghel and Thürk 2019; Klüver and Zubek 2018).

Some governments are 'caught' by the outbreak of the virus during a transitional period, during which a caretaker government with limited authority is in power. Governments were caught by the virus under different political and institutional conditions. Whereas some countries' governments were caught by the virus during their regular term of office, others were caught during a period of transition. Belgium, for example, was 'hit' during the watch of the caretaker and minority government of prime minister Wilmes (Wilmes I). Attempts to form a government failed on March 15 and parliament sanctioned Wilmes II. Her government obtained special powers by a parliamentary mandate to address the coronavirus for the coming period. When the first infection case was reported in Ireland on 27 February 2020, the Irish government of Taoiseach Varadkar, too, had a caretaker status, since none of the party leaders managed to be appointed prime minister after the general elections that were held two weeks earlier on the 8th of February. We expect the transaction costs of policy response adoption are higher to caretaker governments as they lack the necessary mandate to govern by popular consent.

\section{Party-political ideology}

While the factors considered so far capture the capacities of governments and the constraints they face when formulating and adopting policies, the next set of factors looks at their preferences over different policy responses to the crisis. To analyze the effect of government preferences and interests, we look at the political ideology positions of the main parties in cabinet (we operationalize the main party as the party of the prime minister, which works for most countries, with the exception of 
Switzerland, where the prime-ministerial post rotates). We consider the ideological positions along three dimensions, as defined by the Chapel Hill expert survey team: a general left-right dimension, an economic left-right dimension and a GAL/TAN (green/alternative/libertarian vs. traditional/authoritarian/nationalist) dimension (Bakker et al. 2015) ${ }^{15}$.

During the COVID-19 outbreak, one of the most imminent dilemmas that cabinets encounter is the weighting of health care values versus social and economic values. Although both economically right-wing and left-wing parties, i.e. liberal versus labour parties, may value economic values relatively higher vis-a-vis social, i.e. health, values than parties that have a less clear economic profile, we expect that left-wing parties will be more inclined to adopt measures more early in the process of the outbreak than rightwing parties because of the former's higher attachment to social values, such as protection of the weaker groups from being infected, than the more economically liberal parties (Hibbs 1977). Accordingly, we expect that main governing parties towards the right end of the economic left/right scale to be slower in adopting school closures, stay-at-home orders and national lockdowns, because of the impact of such measures on economic activity and the difficulties they create for businesses and employers in particular. Not only are economically right-wing (liberal) parties predisposed to protecting the interests of business actors; they are also expected to oppose the state intervention in the economy that would be needed to mitigate the effects of lockdowns on economic growth, unemployment and bankruptcies, including direct financial support for citizens, massive state aid for big companies and large-scale support measures for small and medium-sized enterprises.

Parties espousing traditional, authoritarian and nationalist values in their ideology, however, are expected to adopt faster and more heavy-handed restrictive measures. Such parties believe in the authority of the state to manage society in what others would consider obtrusive ways and to limit individual liberties and freedoms for the benefit of society at large. Such parties are especially likely to resort to emergency measures and declare states of emergency to handle the crisis, because they are interested in expanding and centralizing the power of the state more generally.

As the general left-right dimension is a composite of the economic and GAL/TAN dimensions, it is harder to articulate a directional hypothesis about its association with the speed and type of policy responses to the COVID-19 pandemic.

\footnotetext{
15 The expert scores for the parties in government in 2020 we use come from the last two available waves of the Chapel Hill survey, so they are in some case rather dated. Once the latest version of the party positions becomes available, the analysis should be replicated with the new numbers.
} 


\section{Societal factors}

The final set of factors we study relates to societal values and the overall freedom of the country. More free societies are expected to have a lower likelihood of having restrictive measures imposed by their governments. In these countries, personal and collective liberties and freedoms are valued, respected, and protected by civil society. Governments face higher thresholds for justifying and enforcing even temporary and partial restrictions on the fundamental freedoms of movement and association. Moreover, respect for freedom is embedded into the political culture and heavy-handed restrictions are not even part of the usual repertoire of policy tools that governments have at their disposal. To measure freedom, we use the Freedom House global freedom score, which is a sum of scores attributed by experts on the qualities of political rights and civil liberties in countries around the world. The score runs from ' 0 ' (no freedom) to '100' (fully free societies).

We also look at the citizens' level of trust in government, a variable we obtained from the most recent Eurobarometer (European Commission 2020). ${ }^{16}$ The effects of trust in government can pull in different directions. On the one hand, when citizens' trust in the government is high, governments have a wider set of policy options to choose from, in the knowledge that whatever the choice, the decision will be respected and complied with by the citizens. On the other hand, because trust in the government is high, the measure the government adopts need not be restrictions and prohibitions back by the power of hard law: recommendations and soft law measures might do just as well. On balance, we expect that countries with higher trust in government to be slower and less likely to impose complete national lockdowns and declare states of emergency.

A similar logic applies to the expected effect of interpersonal trust. ${ }^{17}$ Cabinets in countries in which citizens display high levels of interpersonal trust will feel more confident with stalling the adoption of stringent measures upon their citizens. They can rely on society self-regulating itself, once the appropriate social behaviors have been announced and endorse by the government and experts. In a high-trust social environment, compliance with social distancing can be effectively enforced by social pressure, in theory at least. Such logic has been explicitly used in justifying the lack of school

\footnotetext{
16 Data is available at

https:// ec.europa.eu/commfrontoffice/publicopinion/index.cfm/Survey/getSurveyDetail/instruments/STANDARD/ surveyKy/2255 (last accessed 24 April 2020). National averages retrieved from page T48 of the file of the English Annex. Missing for Switzerland, Norway and Iceland.

17 We obtain the data via the Quality of Government Dataset (available at http://www.qog.pol.gu.se, last consulted 24 April 2020)and take the latest available year for each country
} 
closures and other restrictive measures in $\mathrm{Sweden}^{18}$. Interpersonal trust is measured with reference to the question "Generally speaking, would you say that most people can be trusted or that you need to be very careful in dealing with people?" asked in the various waves of the World Values Survey.

Table A2 in the Supplementary Material presents descriptive information about the variables introduced above that we study empirically in the next sections of the article.

\section{METHOD OF ANALYSIS}

We employ two different modeling strategies to estimate the associations between the timing of policy adoptions and the possible determinants identified in the previous section. The outcome of interest the timing of policy responses relative to the severity of the pandemic for the country at the time of adoption - is difficult to capture with a single measure. Therefore, as explained above, we operationalize it in two different ways: (1) as the cumulative number of confirmed COVID-19 cases at the time of policy adoption; (2) as the number of days between the first confirmed COVID-19 case in the country and policy adoption. The distribution of these two variables is plotted in Figure A1 in the Supplementary Material.

Low numbers of confirmed cases at the date of policy adoption and few days between first case and policy adoption imply that governments have reacted at a relatively early stage of the outbreak. We take the confirmed cases as the main indicator on which governments have acted, as we assume that, especially in the early stages of the outbreak, it was the public and official reports of confirmed cases that fueled public opinion and political debate. Policy makers are assumed to be highly sensitive to the publicly reported confirmed cases in their countries. These reports drove pressures upon the government to adopt suitable measures. So we assume that even if the actual numbers of cases have been (much) higher than the reported ones, it were the official numbers that were of more importance to politicians and policymakers.

We use multivariate linear regression to model the first variable and Cox proportional hazards survival (event history) analysis to model the other two variables. The survival models have the advantage of being able to accommodate the fact that some of our observations are censored, meaning that they had not adopted the policy by the end of our observation period (1 April 2020). However, the number of confirmed cases at the time of policy adoption is arguably a more direct way to measure

\footnotetext{
18 See the article from 21 April 2020 in The Guardian https://www.theguardian.com/world/commentisfree/2020/apr/21/sweden-covid-19-policy-trust-citizens-state (last accessed 24 April 2020)
} 
the current severity of the pandemic for the country. Therefore, we present the results from the linear regression models of this variable in the main text of the analysis, and we detail the results from the survival analysis in the Supplementary Material.

In the multivariate linear regressions presented below, we take the natural logarithm to transform the outcome variable. The censored cases are kept in the data with their values of the outcome variable as of 1 April 2020. We enter the covariates of substantive interest one by one in separate models because of the limited number of observations available (31 at most). The continuous covariates (with the exception of 'number of parties') are scaled (standardized) to have a mean of 0 and a standard deviation of 1 . All models include a control variable for population size. To explore further the possible influence of some of the factors flagged as significant in the initial analyses, we proceed to estimate, present and discuss more complex multivariate models.

\section{EMPIRICAL RESULTS}

Table 1 shows the estimated regression coefficients, standard errors and statistical significance levels for the factors of substantive interest (the coefficients and standard errors for population size are omitted from the table, although all models feature this variable). Each column of the table summarizes the results for each of three policy adoptions: school closures, national lockdowns and states of emergency. As mentioned above, the continuous variables are scaled, so that the size of the regression coefficients is directly comparable across variables. Since the outcome variable is the natural log of the confirmed COVID-19 cases, a regression coefficient of 0.7 implies roughly doubling of the predicted number of cases at which the policy is adopted for a change of 1 unit in the covariate (which would correspond to one standard deviation change for the continuous variables and a change from 0 to 1 for the dichotomous ones). A positive sign of the regression coefficient implies a higher number of cases at the date of policy adoption, hence slower policy reaction, and a negative coefficient implies fewer cases and a faster policy reaction.

As we can see from Table 1, there are a number of significant relationships between the covariates of interest and the three policy outcomes. In particular, the cluster of variables related to general governance capacity is rather strongly and consistently associated with policy timing, such that higher government effectiveness, rule of law, regulatory quality and control of corruption increase the expected number of cases at which the three policies are adopted. 
Table 1. Results from multivariate linear regression models of coronavirus policies in the EU

Variable

Government effectiveness

Control of corruption

Rule of law

Regulatory quality

GDP per capita

Experts (SGI)

Hospital beds

ICU beds

Separate ministry

Minister Med. Doctor

Interpersonal trust

Trust in government

Freedom index

Regionalism

Federalism

Bicameral legislature

Number of parties

Minority government

General Left-Right

Economic Left-Right

GAL-TAN
Coefficient (Standard Error)

Schools

$1.07(0.24) * * *$

$1.13(0.23) * * *$

$1.09(0.23)$ ***

$0.89(0.26) * *$

$0.61(0.29) *$

$0.96(0.25) * * *$

$-0.94(0.26) * *$

$-0.50(0.31)$

$-1.6(0.56) * *$

$-1.63(0.59) * *$

$1.22(0.22) * * *$

$0.68(0.3) *$

$0.99(0.25) * * *$

$0.90(0.36) *$

$1.18(0.92)$

$0.34(0.77)$

$0.32(0.3)$

$0.64(0.64)$

$-0.51(0.31)$

$-0.15(0.32)$

$-0.60(0.3)$.

$0.86(0.26) * *$

$0.94(0.25) * * *$

$0.78(0.27) * *$

$0.52(0.29)$.

$0.6(0.29) *$

$-0.8(0.27) * *$

$-0.65(0.29) *$

Lockdown Emerg. State

$0.82(0.27)$ ** $1.55(0.41)$ *** $\quad 31$

$1.7(0.39) * * * \quad 31$

$1.66(0.39) * * * \quad 31$

$1.36(0.43) * * \quad 31$

$1.19(0.45) *$

$1.22(0.45) *$

$-0.56(0.49)$

$-0.32(0.54)$

$-2.15(0.95) *$

$-0.03(1.08)$

$1.34(0.45)$ **

$0.93(0.51)$.

$1.32(0.44) * *$

$1.62(0.56) * *$

$3.58(1.37) *$

$1.93(1.2)$

$-0.51(0.49)$

$1.23(1.03)$

$0.34(0.52)$

$0.65(0.5)$

$-0.12(0.53)$

Notes: Outcome variable is the natural log of the number of confirmed COVID-19 case at time of policy adoption.

Significance codes: 0 '***' 0.001 '**' 0.01 '*' 0.05 !'0.1

To illustrate the substantive size of the predicted effects, a change of one standard deviation in government effectiveness (0.58 on the original scale of the variable) is associated with an almost $200 \%$ increase in the number of cases at the date at which schools are closed down. GDP per capita also has a significant positive association, meaning richer countries took longer to announce policy restrictions. Surprisingly, the higher the SGI for incorporating expert advice in the early stages of policy making, the slower the government responses, according to the models.

The number of hospital beds (and to a lesser extent the number of ICU beds) has a negative association, supporting the claim that countries with lower health care capacity acted sooner to contain 
the spread of the pandemic on their territory. Having a separate ministry for health has a significant and rather large association with faster policy adoption. So does having a health (or prime) minister with a medical background, but the effect is only significant for school closures. Both interpersonal trust and trust in government have significant positive associations with the number of cases at which the governments acted, and especially in the case of personal trust, the size of the effect is very big (240\% increase for a standard deviation change when it come to school closures and $280 \%$ for declaring a state of emergency). Countries with higher freedom, as measured by the Freedom House, have also been significantly slower in their policy responses, especially when it comes to the adoption of emergency measures.

From the set of institutional variables, both the regionalism and federalism scores seem to increase the number of cases before countries act (remember that all the models control for population size), the effect of regionalism being more precisely estimated. This implies that strong decentralization also impeded the speed of policy responses, in addition to formal federal arrangements.

The rest of the variables that capture institutional and other, government-type, related constraints to decision making, do not have the expected effects, however. Minority governments, coalition governments with a higher number of partners and bicameral legislatures lack significant association with the speed of the policy response. This might be the case because governments acted early to concentrate decision making within the core executive and sideline legislatures and lengthy intra-cabinet negotiations. In Belgium, the minority cabinet of prime minister Wilmes was delegated special powers by all main political parties on $15 \mathrm{March}$, and became cabinet Wilmes II, while it still had a caretaker status.

Finally, there is no evidence that general and left-right party ideology of the main party in government have significant associations with the policy adoptions. Governing parties towards the authoritarian end of the GAL/TAN dimensions, however, seem to have acted significantly faster to close down schools and impose national lockdowns.

The survival models reported in the Supplementary Material mostly support these inferences despite the different outcome variable (number of days between first case and policy adoption) and modeling strategy. Some of the effects are less precisely estimated, but altogether the direction of all associations is consistent across the two sets of models.

All the models presented in Table 1 enter the covariates of interest one by one, so they do not control for possible confounding influences (other than population size). With the type of data that 
we have, identifying and estimating truly causal effects is extremely difficult. Accordingly, we interpret our results mostly in associational terms. But it is still worth exploring whether the influence of some of the variables of interest will be robust to including other covariates in the models.

Table 2. Results from additional multivariate regression models of school closure

\begin{tabular}{|c|c|c|c|c|}
\hline Variable & $\begin{array}{c}\text { Model } 1 \\
\text { Coef. (St.Error) }\end{array}$ & $\begin{array}{c}\text { Model } 2 \\
\text { Coef. (St.Error) }\end{array}$ & $\begin{array}{c}\text { Model } 3 \\
\text { Coef. (St.Error) }\end{array}$ & $\begin{array}{c}\text { Model } 4 \\
\text { Coef. (St.Error) }\end{array}$ \\
\hline Population & $0.04(0.01) *$ & $0.04(0.01)^{* *}$ & $0.04(0.01)$ ** & $0.03(0.01)$ \\
\hline Date first case & $-0.07(0.02) * *$ & $-0.06(0.02) *$ & $-0.05(0.02) *$ & $-0.08(0.02) * * *$ \\
\hline Government effectiveness & $0.72(0.32) *$ & $0.78(0.3) *$ & & \\
\hline GDP per capita & $0.04(0.31)$ & $-0.2(0.27)$ & & \\
\hline ICU units & $-0.39(0.24)$ & & & \\
\hline Hospital beds & & $-0.5(0.22) *$ & & \\
\hline Interpersonal trust & & & $0.82(0.26) * *$ & \\
\hline Freedom Score & & & $0.24(0.26)$ & \\
\hline Separate ministry & & & & $-0.91(0.43) *$ \\
\hline Minister med. doctor & & & & $-1.35(0.43) * *$ \\
\hline
\end{tabular}

Notes: Outcome variable is the natural log of the number of confirmed COVID-19 case at time of policy adoption.

Significance codes: 0 '***' 0.001 '**' 0.01 '*’0 0.05 :’0.1

For example, it could be that low health care capacity confounds the relationship between general governance capacity and the speed of the response. It is also interesting to see whether interpersonal trust and freedoms have separate effects, and whether the influence of having a medical doctor as a minister is separate from the effect of having a ministry of health that is not subsumed or merged with other portfolios. Furthermore, it is possible that some of these associations can be accounted for by the fact that some countries - and the bigger ones being those occupying a more central position in the globalized world, in particular - were hit earlier from the pandemic and this explains why they took longer to react. To explore these possibilities, Table 2 reports another set of four linear regression models of school closures that include the date of the first reported COVID-19 case as a covariate, in addition to population size, and other variables of interests. In all four models, the date of the first case is negatively associated with the number of cases at which policies are adopted, 
so that the later the date, the fewer the cases. However, the rest of the covariates of interest remain significant. Importantly, in Models 1 and 2 government effectiveness remains significant even after we include GDP per capita and indicators for health care capacity, although the size of the coefficient drops. This implies that concerns about health care capacity might be one mechanism that drives the negative association between government effectiveness and the speed of the policy response, but it is not the only mechanism.

According to Model 3, including interpersonal trust and freedom in the same model leads to the latter being no longer significant, but the two are rather highly correlated so there is not much information in the dataset to allow estimating both effects at the same time with enough precision. Looking at Model 4, we can infer that the personal and organizational channels for the effect of the importance of health care in the cabinet work separately, with both effects retaining their significance.

\section{CONCLUSION}

In this study we set out to uncover political, institutional, social and governance-related factors that could account for the variation and the types and timing of the policy responses of the European governments to the initial spread of the COVID-19 pandemic in Europe during the first three months of 2020. Our study of the timing of three policy measures: school closures, national lockdowns and states of emergence revealed a number of interesting associations.

Perhaps most surprisingly, higher government effectiveness and related indicators such as regulatory quality, rule of law, and the incorporation of experts in strategic policy making turned out to be negatively associated with the speed of the policy response across all three policy measures and different statistical model specifications. To some extent, this negative association might be driven by the fact that countries in which the coronavirus hit first happened to be those with higher values on these variables. But this cannot be the whole story, as the additional analyses proved robust to the inclusion of this variable. We offer a different interpretation that rests on a causal link between government effectiveness and the speed of the response: less effective governments in relatively

poorer countries were aware of their limited capabilities of handling a major health crisis and chose to act fast and heavy-handedly to contain the spread of the virus. Yet, when we proxy the perceived threat of the virus by the available hospital and ICU beds in a country, this does not completely remove the association between government effectiveness and the timing of policy responses, suggesting that there are also other mechanisms at play. Institutional and organizational legacies might have played a role as well, as Eastern European governments tend to have a separate ministry of health that is not 
merged or subsumed under different portfolios. Of course, it could also be that existing measures of governance capacity, such as the World Bank Governance Indicator that we use, miss important dimensions of policy-making capacity ${ }^{19}$.

Our analyses suggest that societies with higher interpersonal trust, trust in government and general freedom scores reacted slower to the spread of the pandemic. It could be that where trust is high, the government does not need to intervene with restrictive measures but can rely on people following social distancing recommendations. Anecdotal evidence from Sweden seems to support this view. Countries with higher freedom might have also been more reluctant to restrict the personal liberties and freedoms of citizens that come with lockdowns and emergency measures. Historical legacies might play a role in accounting for these associations as well, with countries in CEE with more recent experiences of authoritarianism being faster in closing schools and public spaces, imposing lockdowns and even curfews, and restricting the free movement of its citizens across its territories.

It is also remarkable that from the three dimensions of party political preferences that we explored as possible determinants of the policy responses, only the positions of the governing parties on the traditional/authoritarian/nationalist dimension seem to be related with the policy responses, with governing parties scoring higher on this dimensions being marginally faster in imposing national lockdowns and closing down schools. We find no evidence that general and economic left-right positions played a role ${ }^{20}$, but we should note that the data on party positions we use is dated. This is in contrast to evidence from the US, where it does seem that the party affiliation of the state governor made a difference (Adolph et al. 2020).

From the institutional factors that we examined, regionalism and federalism have significant negative association with the speed of the response, but the number of chambers of the national legislature does not. So, while more complex vertical distribution of power within the state might have impeded the speed and scope of the policy reactions (as evidence from Germany also suggests), horizontal constraints on government action have not played a role. This is also in line with the lack of significant effects for the type of government (minority, caretaker or majority) and the number of governing parties in the coalition. This lack of effect is perhaps explained by the fact that most

\footnotetext{
${ }^{19}$ For instance, in the context of managing the pandemic and the comprehensive testing this requires, the UK has been criticized for missing universal personal registration systems, which is a crucial infrastructure for effective governance.

${ }^{20}$ In a remarkable demonstration of the lack of importance of party ideology for managing the crisis, the Dutch cabinet appointed a member of the opposition as its health minister during the most crucial days of the pandemic (the incumbent minister having resigned due to exhaustion).
} 
governments passed some kind of emergency measures that strengthened the executive, streamlined decision making, and delegated daily management of the pandemic to special councils and committees.

We should emphasize that our study is focused primarily on the speed of the policy responses with respect to three specific restrictive measures, and this should not be equated with the quality of the overall policy response. Other aspects of the policy responses, such as their legitimacy in the eyes of the citizens, their strategic coordination, or their uniform implementation are as valuable, if not more so, than the speed as such. However, when we look at the effectiveness of the policy measures for containing and slowing down the spread of the coronavirus in the population as well as for limiting its impact on mortality, it appears that the speed of the response has been of paramount importance. Perhaps countries with more established traditions of seeking expert advice and higher governance capacity have been too prudent in waiting for solid evidence about the severity, likely trajectory and impact of the pandemic, before they have decided that the risks are significant enough to warrant the drastic economic and social consequences from lockdowns. But with the benefit of hindsight we now know that the risks, as they appeared in February and early March 2020, had been underestimated. Now we know that the likely number of infected people had been higher than the officially-registered cases at the time, that the prevalence of asymptomatic cases had been much higher than anticipated, and that the virus could be transmitted easier than many believed in February. The policies of the countries with higher governance capacity could have been appropriate for the perceived risks as of February and early March 2020, but not to the actual risks as we understand them a month afterwards. So when it comes to the policy effectiveness of policy responses to COVID-19, in this particular case the speed of the response outweighs other considerations about the quality of the policy process.

How do our results travel outside the set of European cases that we study? One group of countries that fits the pattern that less effective governments and less free societies adopt quite hastily far-reaching restrictions on social life and internal movement is the group of Western Balkan countries (Serbia, Northern Macedonia, Albania, and others). These countries imposed and enforced heavyhandedly lockdowns and curfews relatively early in the course of the pandemic. When it comes to truly autocratic governments, however, it looks like restrictions can come either very fast or very slow. Belarus is a case in point, with President Lukashenka ignoring the pandemic for many weeks, to a lesser extent Russia, which waited a rather long while before adopting serious restrictive measures, and, most disturbingly of all, Turkmenistan, where the word 'coronavirus' itself was forbidden. As for government effectiveness, some of the countries that have been praised so far for the quality of their policy response to the pandemic - South Korea, New Zealand, Australia - score very highly on 
measures of government effectiveness. But then there are countries that do not and still acted quite fast, such as India and other states in South East Asia, and some rich countries, such as the US, developed only a delayed, inconsistent and poorly articulated response. Exploring more systematically our results in a global sample of countries will be worthy exercise.

If our results have any implications for the practice of crisis management and dealing with global health pandemics, it is the insight that when such a crisis hits, risk-averse governments acting fast without too much evidence supporting tough actions being available yet might fare better than governments with more capacities that wait until proper expert advice and evidence is collected and assessed. As the COVID-19 crisis has made clear so far, it has been better to err on the side of caution, by acting fast and decisively. Further, while societies with higher levels of interpersonal trust and freedoms make it less likely that restrictive policies will be adopted, social self-regulation might work to some extent but does not have the same effect as official bans and lockdowns enforced by state authorities. There is a tradeoff between the positive effects of tough policies on mortality and the spread of the virus and their negative effects on personal liberties and freedoms, but this tradeoff needs to be openly acknowledged. Finally, one insight from our study with very direct practical implications is the result that countries in which the ministry of health was not shared or subsumed under other portfolios and where the health minister had a medical background acted faster to contain the pandemic. The organizational change to government structures implied by this result is relatively easy to implement. But our study is associational and in the absence of causal inference claims, such recommendations should be taken as preliminary.

In fact, we see one major direction for further research in designing and implementing research designs that can deliver stronger causal inferences about the impact of individual factors than we are able to provide in the current study. Our analyses are exploratory and our results should be considered as providing causal hypotheses for further research rather than establishing and estimating causal effects as such. Nonetheless, the associational results we provide remain useful in their own right and identify promising areas for future research.

Our study is focused on the policy responses to the first stages of the COVID-19 pandemic. As we complete this text, European countries are deciding whether, when and how to gradually open schools, shops and public areas in light of evidence that the growth in the number of infected people and deaths from the virus is slowing or reversing. It will be interesting to see whether our results will remain relevant in accounting for government actions in the next stages in the fight against this global pandemic. 


\section{REFERENCES}

Adolph, Christopher et al. 2020. Pandemic Politics: Timing State-Level Social Distancing Responses to COVID19. Health Policy. preprint. http://medrxiv.org/lookup/doi/10.1101/2020.03.30.20046326 (April 27, 2020).

Anghel, Veronica, and Maria Thürk. 2019. "Under the Influence: Pay-Offs to Legislative Support Parties under Minority Governments." Government and Opposition: 1-20.

Bakker, Ryan et al. 2015. "Measuring Party Positions in Europe: The Chapel Hill Expert Survey Trend File, 1999-2010.” Party Politics 21(1): 143-52.

Baldwin, Robert, Martin Cave, and Martin Lodge. 2011. Understanding Regulation: Theory, Strategy, and Practice. Second Edition. Oxford: Oxford University Press.

Boeke, Sergei. 2018. "National Cyber Crisis Management: Different European Approaches." Governance 31(3): 449-64.

Boin, Arjen, and Fredrik Bynander. 2015. "Explaining Success and Failure in Crisis Coordination." Geografiska Annaler: Series A, Physical Geography 97(1): 123-35.

Boin, Arjen, and Paul 't Hart. 2012. "Aligning Executive Action in Times of Adversity: The Politics of Crisis Co-Ordination." In Executive Politics in Times of Crisis, The Executive Politics and Governance series, eds. Martin Lodge and Kai Wegrich. London: Palgrave Macmillan UK, 179-96.

Boswell, John. 2018. "What Makes Evidence-Based Policy Making Such a Useful Myth? The Case of NICE Guidance on Bariatric Surgery in the United Kingdom.” Governance 31(2): 199-214.

Christensen, Tom, Per Lægreid, and Lise H. Rykkja. 2016. "Organizing for Crisis Management: Building Governance Capacity and Legitimacy.” Public Administration Review 76(6): 887-97.

European Commission. 2020. "Eurobarometer 92.3 (2019). Kantar Public [Producer]." https://data.europa.eu/euodp/en/data/dataset/S2255_92_3_STD92_ENG (April 23, 2020).

Friedson, Andrew I, Drew McNichols, Joseph J Sabia, and Dhaval Dave. 2020. Did California's Shelterin-Place Order Work? Early Coronavirus-Related Public Health Effects. National Bureau of Economic Research. Working Paper. http://www.nber.org/papers/w26992 (April 27, 2020).

Hale, Thomas et al. 2020. "Coronavirus Government Response Tracker | Blavatnik School of Government. Data Use Policy: Creative Commons Attribution CC BY Standard." https://www.bsg.ox.ac.uk/research/research-projects/coronavirus-government-responsetracker (April 23, 2020).

Hammond, Thomas H. 1986. "Agenda Control, Organizational Structure, and Bureaucratic Politics." American Journal of Political Science 30(2): 379-420.

Hibbs, Douglas A. 1977. "Political Parties and Macroeconomic Policy." The American Political Science Review 71(4): 1467-87. 
Hooghe, Liesbet et al. 2016. Measuring Regional Authority: A Postfunctionalist Theory of Governance, Volume I. Oxford: Oxford University Press.

Howlett, Michael, Anthony Perl, and M. Ramesh. 2009. Studying Public Policy: Policy Cycles \& Policy Subsystems. Oxford: Oxford University Press.

Jabko, Nicolas. 2019. "Contested Governance: The New Repertoire of the Eurozone Crisis." Governance 32(3): 493-509.

King, Anthony. 1976. "Modes of Executive-Legislative Relations: Great Britain, France, and West Germany." Legislative Studies Quarterly 1(1): 11-36.

Klüver, Heike, and Radoslaw Zubek. 2018. "Minority Governments and Legislative Reliability: Evidence from Denmark and Sweden." Party Politics 24(6): 719-30.

Meckling, Jonas, and Jonas Nahm. 2018. "The Power of Process: State Capacity and Climate Policy." Governance 31(4): 741-57.

Mortensen, Peter B., and Christoffer Green-Pedersen. 2015. "Institutional Effects of Changes in Political Attention: Explaining Organizational Changes in the Top Bureaucracy." Journal of Public Administration Research and Theory 25(1): 165-89.

Oliver, Adam. 2020. "HEPL Blog Series: Country Responses to the Covid19 Pandemic." Cambridge Core. /core/journals/health-economics-policy-and-law/hepl-blog-series-covid19-pandemic (April 27, 2020).

Rasch, Bjorn Erik, and George Tsebelis, eds. 2011. The Role of Governments in Legislative Agenda Setting. New York: Routledge.

Schimmelfennig, Frank, Dirk Leuffen, and Berthold Rittberger. 2015. "The European Union as a System of Differentiated Integration: Interdependence, Politicization and Differentiation." Journal of European Public Policy 22(6): 764-82.

Spiteri, Gianfranco et al. 2020. "First Cases of Coronavirus Disease 2019 (COVID-19) in the WHO European Region, 24 January to 21 February 2020." Eurosurveillance 25(9). https://www.eurosurveillance.org/content/10.2807/1560-7917.ES.2020.25.9.2000178 (April 27, 2020).

Toshkov, Dimiter, Lars Mäder, and Anne Rasmussen. 2020. "Party Government and Policy Responsiveness. Evidence from Three Parliamentary Democracies." Journal of Public Policy 40(2): 329-47.

Tsebelis, George. 2011. Veto Players: How Political Institutions Work. Princeton, N.J.: Princeton University Press. 


\section{SUPPLEMENTARY MATERIAL}

\section{Part A1 Descriptive statistics}

Figure 1. Density (distribution) of the two outcome variables used in the linear regression (top) and the survival models (bottom)

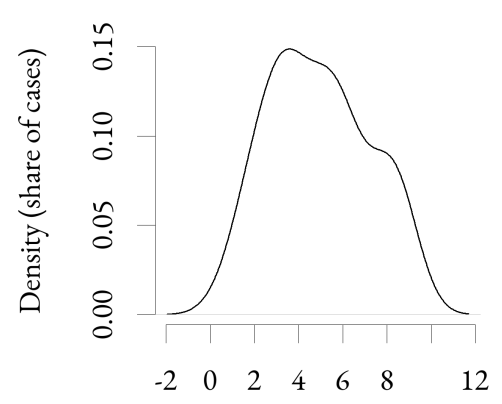

School closure

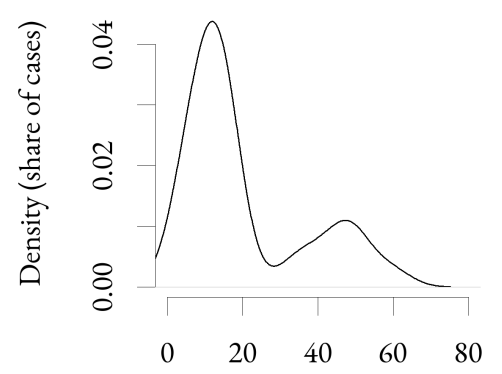

School closure
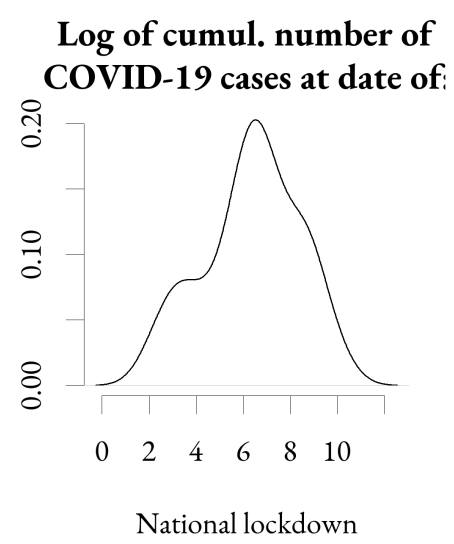

Number of days between

first case and date of:

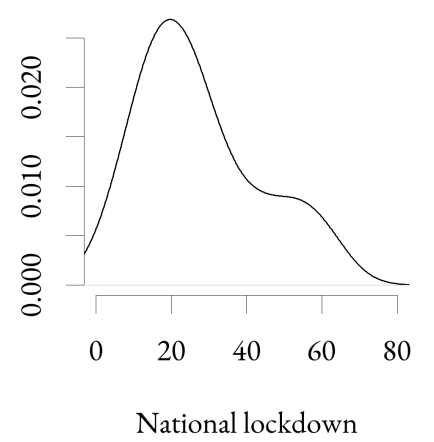


Table A1. Descriptive information about the national policies analyzed in the models.

\begin{tabular}{|c|c|c|c|c|c|}
\hline \multicolumn{2}{|r|}{ Country } & School closure & National lockdown & State of emergency & Emergency measures \\
\hline Name & Population First case & $\mathbf{N}$ cases at Date & $\mathbf{N}$ cases at Date & $\mathbf{N}$ cases at Date & $\mathbf{N}$ cases at Date \\
\hline Austria & 8.8 mil 26 Feb 2020 & 24612 Mar 2020 & 86016 Mar 2020 & 10182 & 10182 \\
\hline Belgium & 11.4 mil 04 Feb 2020 & 31412 Mar 2020 & 108517 Mar 2020 & 12775 & 68915 Mar 2020 \\
\hline Bulgaria & 7 mil 08 Mar 2020 & 2313 Mar 2020 & 2313 Mar 2020 & 2313 Mar 2020 & 2313 Mar 2020 \\
\hline Croatia & $4.1 \mathrm{mil} 26 \mathrm{Feb} 2020$ & 2513 Mar 2020 & 5617 Mar 2020 & 867 & 867 \\
\hline Cyprus & 1.2 mil 10 Mar 2020 & 613 Mar 2020 & 11624 Mar 2020 & 2115 Mar 2020 & 2115 Mar 2020 \\
\hline Czech Republic & 10.7 mil02 Mar 2020 & 4010 Mar 2020 & 29816 Mar 2020 & 9412 Mar 2020 & 9412 Mar 2020 \\
\hline Denmark & 5.8 mil 27 Feb 2020 & 26411 Mar 2020 & 67613 Mar 2020 & 2860 & 102418 Mar 2020 \\
\hline Estonia & $1.3 \mathrm{mil} 28 \mathrm{Feb} 2020$ & 17116 Mar 2020 & 745 & 1612 Mar 2020 & 1612 Mar 2020 \\
\hline Finland & 5.5 mil 30 Jan 2020 & 26716 Mar 2020 & 1384 & $26716 \mathrm{Mar} 2020$ & 26716 Mar 2020 \\
\hline France & 67 mil 25 Jan 2020 & 366114 Mar 2020 & 663317 Mar 2020 & 52128 & 1445922 Mar 2020 \\
\hline Germany & 82.9 mil 28 Jan 2020 & 483816 Mar 2020 & 2146322 Mar 2020 & 67366 & 3155425 Mar 2020 \\
\hline Greece & 10.7 mil 27 Feb 2020 & 9011 Mar 2020 & 62423 Mar 2020 & 1314 & 1314 \\
\hline Hungary & 9.8 mil05 Mar 2020 & 3916 Mar 2020 & 34328 Mar 2020 & 1211 Mar 2020 & 1211 Mar 2020 \\
\hline Iceland & 0.4 mil 29 Feb 2020 & 19917 Mar 2020 & 1135 & 1135 & 1135 \\
\hline Ireland & 4.9 mil01 Mar 2020 & 4312 Mar 2020 & 181927 Mar 2020 & 3235 & 36619 Mar 2020 \\
\hline Italy & 60.4 mil 31 Jan 2020 & 250204 Mar 2020 & 1014911 Mar 2020 & 331 Jan 2020 & 331 Jan 2020 \\
\hline Latvia & 1.9 mil 03 Mar 2020 & 1012 Mar 2020 & 398 & 1012 Mar 2020 & 1012 Mar 2020 \\
\hline Lithuania & $2.8 \mathrm{mil} 28 \mathrm{Feb} 2020$ & 312 Mar 2020 & 1416 Mar 2020 & 026 Feb 2020 & 026 Feb 2020 \\
\hline Luxembourg & 0.6 mil01 Mar 2020 & 2613 Mar 2020 & 3815 Mar 2020 & 14018 Mar 2020 & 14018 Mar 2020 \\
\hline Malta & 0.5 mil08 Mar 2020 & 612 Mar 2020 & 167 & 16701 Apr 2020 & 16701 Apr 2020 \\
\hline Netherlands & 17.2 mil 28 Feb 2020 & 95915 Mar 2020 & 420423 Mar 2020 & 12595 & 12595 \\
\hline Norway & 5.3 mil $27 \mathrm{Feb} 2020$ & 48912 Mar 2020 & 48912 Mar 2020 & 4447 & 174221 Mar 2020 \\
\hline Poland & 38 mil04 Mar 2020 & 3112 Mar 2020 & 3112 Mar 2020 & 2311 & 2311 \\
\hline Portugal & 10.3 mil 03 Mar 2020 & 24516 Mar 2020 & 64219 Mar 2020 & 44818 Mar 2020 & 44818 Mar 2020 \\
\hline Romania & 19.5 mil 27 Feb 2020 & 1509 Mar 2020 & 76225 Mar 2020 & 8914 Mar 2020 & 8914 Mar 2020 \\
\hline Slovakia & 5.4 mil 07 Mar 2020 & 1012 Mar 2020 & 1012 Mar 2020 & 4415 Mar 2020 & 4415 Mar 2020 \\
\hline Slovenia & $2.1 \mathrm{mil} 05 \mathrm{Mar} 2020$ & 5712 Mar 2020 & 31920 Mar 2020 & 5712 Mar 2020 & 5712 Mar 2020 \\
\hline Spain & 46.7 mil01 Feb 2020 & 423114 Mar 2020 & 423114 Mar 2020 & 423114 Mar 2020 & 423114 Mar 2020 \\
\hline Sweden & 10.2 mil01 Feb 2020 & 4435 & 4435 & 4435 & 4435 \\
\hline Switzerland & 8.5 mil 26 Feb 2020 & 85413 Mar 2020 & 697123 Mar 2020 & 16108 & 220016 Mar 2020 \\
\hline United Kingdom & 66.5 mil 31 Jan 2020 & 568323 Mar 2020 & 568323 Mar 2020 & 25150 & 807725 Mar 2020 \\
\hline
\end{tabular}


Table A2. Descriptive statistics of the covariates used in the models.

Variable name Minimum Maximum Mean St.dev.

$\begin{array}{lllll}\text { Government effectiveness } & -0.25 & 2.04 & 1.15 & 0.58\end{array}$

$\begin{array}{llllll}\text { Control of corruption } & -0.15 & 2.21 & 1.09 & 0.81\end{array}$

$\begin{array}{lllll}\text { Rule of law } & -0.03 & 2.05 & 1.17 & 0.62\end{array}$

$\begin{array}{llllll}\text { Regulatory quality } & 0.3 & 2.02 & 1.22 & 0.49\end{array}$

$\begin{array}{llllll}\text { GDP per capita } & 21.96 & 113.34 & 46.17 & 18.51\end{array}$

$\begin{array}{lllll}\text { Experts (SGI) } & 2 & 9 & 5.61 & 1.71\end{array}$

$\begin{array}{lllll}\text { Hospital beds } & 2.22 & 8 & 4.76 & 1.64\end{array}$

$\begin{array}{lllll}\text { ICU beds } & 4.2 & 33.9 & 11.8 & 6.6\end{array}$

$\begin{array}{lllll}\text { Separate ministry } & 0 & 1 & 0.61 & 0.5\end{array}$

$\begin{array}{lllll}\text { Minister med. doctor } & 0 & 1 & 0.32 & 0.48\end{array}$

$\begin{array}{llllll}\text { Personal trust } & 8 & 76 & 34.53 & 18.88\end{array}$

$\begin{array}{lllll}\text { Trust in government } & 15 & 68 & 38.43 & 14.29\end{array}$

$\begin{array}{lllll}\text { Freedom index } & 70 & 100 & 91.81 & 6.53\end{array}$

$\begin{array}{lllll}\text { Regionalism } & 0 & 37.4 & 11.51 & 10.51\end{array}$

$\begin{array}{lllll}\text { Federalism } & 0 & 1 & 0.13 & 0.34\end{array}$

$\begin{array}{lllll}\text { Bicameral legislature } & 0 & 1 & 0.45 & 0.51\end{array}$

$\begin{array}{lllll}\text { Number of parties } & 1 & 5 & 2.65 & 1.36\end{array}$

$\begin{array}{llllll}\text { Minority government } & 0 & 1 & 0.39 & 0.5\end{array}$

$\begin{array}{lllll}\text { General Left-Right } & 2.12 & 8.73 & 5.7 & 1.78\end{array}$

$\begin{array}{lllll}\text { Economic Left-Right } & 2 & 8.6 & 5.44 & 2.04\end{array}$

$\begin{array}{lllll}\text { GAL-TAN } & 0.5 & 9.24 & 5.18 & 2.14\end{array}$

Notes: Data compiled from multiple sources (see text for details). 


\section{Part A2 Survival models I}

Table A3. Results from Cox proportional hazards survival models of coronavirus policies in the EU

Variable

\begin{tabular}{|c|c|c|c|}
\hline & Schools & Lockdown & Emerg. state \\
\hline Government effectiveness & $-0.63(0.2) * *$ & $-0.4(0.2) *$ & $-0.56(0.2) * *$ \\
\hline Control of corruption & $-0.76(0.21) * * *$ & $-0.51(0.22) *$ & $-0.63(0.21) * *$ \\
\hline Rule of law & $-0.67(0.2) * * *$ & $-0.59(0.23) *$ & $-0.6(0.2) * *$ \\
\hline Regulatory quality & $-0.54(0.19) * *$ & $-0.49(0.21) *$ & $-0.45(0.19) *$ \\
\hline GDP per capita & $-0.35(0.28)$ & $-0.08(0.27)$ & $-0.32(0.27)$ \\
\hline Experts (SGI) & $-0.66(0.21) * *$ & $-0.47(0.22) *$ & $-0.49(0.23) *$ \\
\hline Hospital beds & $0.48(0.2) *$ & $0.36(0.21)$ & $0.24(0.21)$ \\
\hline ICU beds & $0.2(0.19)$ & $0.14(0.2)$ & $0.09(0.2)$ \\
\hline Separate ministry & $0.47(0.38)$ & $0.2(0.41)$ & $0.71(0.43)$ \\
\hline Minister med. doctor & $0.43(0.4)$ & $0.21(0.43)$ & $-0.03(0.44)$ \\
\hline Personal trust & $-0.93(0.27) * * *$ & $-0.59(0.27) *$ & $-0.62(0.26) *$ \\
\hline Trust in government & $-0.33(0.2)$. & $-0.37(0.25)$ & $-0.25(0.2)$ \\
\hline Freedom index & $-0.57(0.17) * * *$ & $-0.37(0.18) *$ & $-0.57(0.21) * *$ \\
\hline Regionalism & $-0.24(0.23)$ & $-0.03(0.23)$ & $-0.27(0.25)$ \\
\hline Federalism & $-0.26(0.55)$ & $-0.07(0.56)$ & $-0.51(0.56)$ \\
\hline Bicameral legislature & $0.49(0.47)$ & $0.63(0.5)$ & $0.33(0.48)$ \\
\hline Number of parties & $-0.15(0.2)$ & $-0.23(0.2)$ & $-0.18(0.22)$ \\
\hline Minority government & $-0.26(0.4)$ & $0.29(0.42)$ & $0.07(0.44)$ \\
\hline General Left-Right & $0.3(0.2)$ & $0.29(0.22)$ & $0.11(0.22)$ \\
\hline Economic Left-Right & $0.23(0.2)$ & $0.22(0.22)$ & $0.03(0.21)$ \\
\hline GAL-TAN & $0.23(0.22)$ & $0.44(0.24)$. & $0.22(0.22)$ \\
\hline
\end{tabular}

Notes: Outcome variable is number of days between first conformed COVID-19 case and policy adoption.

Significance codes: 0 '***'0.001 '**' 0.01 '*' 0.05 ?’0.1

\section{Coefficient (Standard Error)}

Lockdown Emerg. state

$$
\begin{aligned}
& -0.4(0.2) * \quad-0.56(0.2) \text { ** } \\
& -0.51(0.22) * \quad-0.63(0.21) \text { ** } \\
& -0.6(0.2) * * \\
& -0.08(0.27) \\
& -0.47(0.22) * \quad-0.49(0.23) \text { * } \\
& 0.36(0.21) \text {. } 0.24(0.21) \\
& 0.14(0.2) \quad 0.09(0.2) \\
& 0.71(0.43) \\
& 0.59(0.27) * \quad-0.62(0.26) * \\
& -0.37(0.25) \quad-0.25(0.2) \\
& -0.03(0.23)+-0.57(0.21) * * \\
& -0.07(0.56) \quad-0.51(0.56) \\
& 0.63(0.5) \quad 0.33(0.48) \\
& -0.23(0.2) \quad-0.18(0.22) \\
& 0.29(0.42) \quad 0.07(0.44) \\
& 0.29(0.22) \quad 0.11(0.22) \\
& 0.22(0.22) \quad 0.03(0.21) \\
& 0.44(0.24) \text {. } \quad 0.22(0.22)
\end{aligned}
$$

